\title{
ICT Education and Training in Sub-Saharan Africa: Multimode versus Traditional Distance Learning
}

\author{
JC (Joey) Jansen van Vuuren and FP (Petrie) Coetzee \\ Technikon Pretoria, Pretoria, South Africa
}

\author{
jvvuuren@techpta.ac.za petrie@techpta.ac.za
}

\begin{abstract}
The concept of distance learning by advanced educational technology is at present only emerging in Africa. This applies particularly to education and training in information and communication technology (ICT). A learner support system needs to be put in place to assist students to use relevant technologies. Learners in Africa tend to have difficulty understanding the technologies underpinning the ICT era. Research shows that distance learning requires much self-discipline on the part of students. Compared to conventional learning, students tend to become more isolated in distance-learning programmes. Strategies to reduce negative factors should be put in place to ensure the increase of competent ICT specialists in Africa. The strategy recommended here is a multimode strategy incorporating both face-to-face and e-learning into distance learning environments, customized according to subject content.
\end{abstract}

Keywords: E-learning, Distance learning, Multimode learning, ICT Education

\section{Introduction}

In general distance learning means learning in which the learner is distant from the education institution providing the relevant tuition. In this paper we use the term "traditional distance learning", denoting thereby distance learning conducted mainly through snail-mail but also including limited face-to-face contact. We use the term "multimode learning" to denote distance learning in which the tuition is provided through virtual or e-learning, that is, through online interactive learning, but also including into this notion face-to-face contact, more extensively than with traditional distance learning. Our concern is with information and communication technology (ICT) education and training in Sub-Saharan Africa. For the sake of brevity we will use the term "Africa" when intending reference merely to Sub-Saharan Africa, while excluding Northern Africa, simply because we are uncertain about conditions and the situation in that region.

"The growing importance of ICT service providers and training centers coupled with steady increases in the number of users, bear testimony to the spread of IT in African countries" (Gilpin, 2000). The lack of information and communication technologies in developing countries has been widely emphasised during the last decade (Odedra-Straub, 2002). Distance education in general, and distance education using advanced technology in particular, has not been very successful in

Material published as part of this journal, either on-line or in print, is copyrighted by Informing Science. Permission to make digital or paper copy of part or all of these works for personal or classroom use is granted without fee provided that the copies are not made or distributed for profit or commercial advantage AND that copies 1) bear this notice in full and 2) give the full citation on the first page. It is permissible to abstract these works so long as credit is given. To copy in all other cases or to republish or to post on a server or to redistribute to lists requires specific permission from the publisher at Publisher@InformingScience.org
Africa. This is due to various factors: poverty, lack of infrastructure, illiteracy, lack of language skills in respect of major international languages, and so forth. This paper suggests that multimode learning needs to be introduced to overcome obstacles, as 
against traditional distance education and typical single mode e-learning.

\section{Factors Influencing Virtual or E-Learning Environments in Third World Countries and Africa}

Two clusters of factors influence virtual learning environments in the Third World and particularly in Sub-Saharan Africa, centring on matters bearing on technology, on the one hand, and on education and learning content and media on the other hand.

\section{Factors bearing on technology}

The major factors bearing on technology are those of cost and the availability of telecommunications infrastructure. These are particularly the following:

Computers are expensive - far too expensive for the vast majority of individuals in developing countries. It may perhaps be possible to get sponsors or to have equipment donated to set up a tele-center (a communal Internet and computing facility), but Internet cafés are very few and far between. Internet cafés mostly specialise in e-mail facilities, because browsing on the Internet takes up too much bandwidth. E-mail is also mainly used for communication with family and friends and is not used for studies. The majority of students do not have access to personal computers and the Internet. (Mundy \& Sultan, 2001)

Equipment only is of little use, unless knowledge about how to operate, maintain and adapt such equipment to local conditions accompanies such equipment (Odedra-Straub, 1990). Provision of supplies and maintenance of equipment remains a problem in Africa. Inadequate numbers of maintenance staff are trained and available. Theft, furthermore, increases the cost of maintaining tele-centers. In addition, consumables are very expensive and not readily available to such centers. (Mundy \& Sultan, 2001)

Connection fees and online charges are high in Africa, with telephone companies mostly being state monopolies. (Mundy \& Sultan, 2001; Murphy et al., 2002). Telephone connections are slow and unreliable. There are scarcely any of these in Africa's rural villages, most of which lack basics, such as electricity and roads. (Mundy \& Sultan, 2001)

\section{Factors Bearing on Education and on Learning Content and Media}

Physical access is not the only or even the most important factor influencing ICT education in Africa. Very few African countries can meet educationally sound and inclusive access to ICT (Lelliot, 2000). Although there already are distance education institutions operating in Africa, the success of these institutions differs from country to country. Using ICT as a means of education will not be effective if there is not a certain critical level of education, a condition that in most of Africa has not been met as yet (Lelliot, 2000). The overall literacy rate generally remains low in many regions in Africa (Chale \& Michaud, 1997). In the main stream education systems the school enrolment rates are low, school drop-out rates are high, and teacher-to-pupil ratio's are discouraging (Gilpin, 2000). The ability of learners to do self-study based on prior learning at schools is therefore low. This complicates attempts by students at distance learning. The foundational background in languages acquired at schools is not always adequate for self-study in the major international languages (e.g, English, French) (Mundy \& Sultan, 2001). Research shows that distance learning requires substantial self-discipline on the part of the student, and student isolation tends to be high, compared to conventional learning. (Gilpin, 2000)

Invariably, the decision to develop the infrastructure in Africa is primarily a political one (Chale \& Michaud, 1997). Huge shortages of skilled personnel and high staff turnover in IT firms or related companies in Africa results in significant productivity losses. "Universities and technical 
colleges are often ill equipped to provide training on current technological developments" (Ivala, 1999). Darkwa \& Mazibuko voice a similar opinion (Darkwa \& Mazibuko, 2000).

People in Africa are often still afraid of computers and have difficulty in using the technology. They may, for example, not be able to navigate around a screen using a mouse, neither to understand obscure commands and error messages (Mundy \& Sultan 2001). Teachers are not always familiar with the technological environment and are thus not equipped to use ICT in education. In an opinion document a former Minister of Education from Guinea states, “ . . t teachers who don't master computing skills will necessarily prevent pupils, more eager than they, from using technology. Resistance to change is hard to overcome." (Diallo, n.d.)

Courses and training materials do not always reflect market needs (Ivala, 1999). To worsen the situation, much of the content and style of the materials produced in developed countries is unsuited to social and cultural traditions in less developed countries and may have the effect of excluding people who are already severely disadvantaged (Leilliot 2000). The vast majority of Internet sites are irrelevant to local people. Most of the content on the Internet is probably generated by Europeans and Americans, with English being the most common language on the Internet (Darkwa \& Mazibuko, 2000). People from developing countries, who do not, for example, have English as their home language and who have been inadequately schooled in that language, can hardly easily or adequately relate to computer technology or the Internet. This problem is compounded when students need to actually study in English in distance education.

Currently institutions of tertiary education in Africa cannot accommodate all secondary school graduates. According to research done by the World Bank in Malawi “...of those completing their secondary education only $15 \%$ obtain places at the University of Malawi and University of Mzuzu." This is also the case in other African countries (SAIDE, 1999).

Payment for studies offered via the Internet by foreign institutions or for study materials to be acquired from abroad, is often difficult in Africa due to lack of international currency and /or the cost of such currency. (Odedra-Straub, 1990)

\section{A Need for Alternative Distance Learning Practices in Africa}

Globalisation increases the need for Third World countries to provide infrastructure and expertise for ICT for use in all sectors. General investments in developing countries depend largely on the availability of communication systems to communicate between subsidiary offices and head offices of internationally based companies (Gilpin, 2000). Investment in infrastructure is of little use without accompanying knowledge of the operation and maintenance of equipment. Training for both technicians and educators is thus crucial for the expansion of ICT in Africa. Alternative teaching strategies have to be found to satisfy the demands of the new information era.

Distance learning was one of the first strategies used to offer alternative education in Africa. The cost of distance learning is substantially less than normal face-to-face learning (Chale \& Michaud, 1997). Studies have furthermore shown that distance education can be substantially more cost effective than traditional programmes, but on condition that there is a large student base with good support systems (Darkwa \& Mazibuko, 2000). Not all distance education centers already established in Africa can be classified as successful. In Malawi research has shown that the pass rate of candidates doing their Malawi School Certification Examination by means of distance education has been very low. In 1996 the rate was $11.2 \%$ while it was 9.3\% in 1997. Yet these rates were not inordinately low compared to the overall Malawi School Certification Examination, which produced an overall pass rate of 16.7\% in 1998 (SAIDE, 1999).

Countries with limited educational resources can nevertheless gain access to global training and educational programmes by using alternative ways of distance education. Experience has "shown 
that late teenagers and especially adult students learn more efficiently through two way multiple interactions with human resources", which leads to "recommendations to have multi-mediated and multi-group interactions in the learning process" (Chale \& Michaud, 1997). Traditional distance learning alone is thus not advisable for these groups.

\section{Multimode Learning as a Solution}

To ensure interaction in the learning process, we wish to recommend a multimode type of distance learning in which a relatively more extensive contiguous, face-to-face component is included in an e-learning environment. This mode of distance learning includes multi-media as well as multi-group interactions (chat groups). Facilitators are used for supervision and counselling of students. Facilitation and tutoring can be extended to discussion groups and workshops.

Already in 1996/1997 the Malawi Government identified a variant of this model by changing their Distance Education Centers for secondary schools into Community Day Secondary Schools by introducing a face-to-face component. Unfortunately facilitators were not adequately qualified and materials and other resources were not sufficient, with the result that there was no substantial increase in pass rates (SAIDE, 1999). A similar model has been adopted in Kenya where distance learning programmes are provided by dual modes of instruction. Residential institutions are used for lecturing to distance-learning students on a part time basis.

We suggest that this model will reduce the isolation of students through regular contact between students and facilitators as well as contact between students and peers. Discussions on subject topics and resolution of problems with subject content will speed up the learning process and remove quite a number of frustrations.

Facilitating the learning process can reduce language problems as well as problems flowing from cultural differences by using facilitators of the same culture that can explain topics in the learners' own language. By inclusion of e-learning in the multimode model, materials can be easily updated. E-learning has the additional advantage that use of the Internet provides a learner with a large bedrock of current and historical research material as well as tools for research and other uses.

Using the Internet as medium for distance education creates its own challenges. We submit that it is important to set up learner support systems for assisting students to comprehend all the technical details needed to make effective use of technology.

Further problems associated with using the Internet as only medium of instruction, are security, speed and stress during examinations. A benefit of the multimode model lies in making use of facilitators for local practical evaluations and theoretical examinations. Using local facilitators provides the further advantage that questions and evaluations can be adapted to the local culture and language.

For the multimode model to be implemented successfully, centers need to be set up with appropriate technology, technicians need to be available for maintenance, and qualified lecturers need to be at hand. One of the initiatives to actually do this was the Acacia Initiative from the International Development and Research Centre (IDRC). This initiative has suggested the establishment of ICT based Distance Learning Centers to function as facilities for community institutions, and for individuals, to access the Internet and, thereby other educational programmes. This is meant to present local people the opportunity to engage in continuous learning programmes and for them to participate in modern ICT applicable distance learning (Chale \& Michaud, 1997). Another similar initiative has been launched in South Africa, namely the TELISA initiative (Technology Enhanced Learning Initiative of South Africa), with the aim of setting up a number of ICT centers throughout the Southern Africa Development Community (SADC) region. The infra- 
structure was intended to facilitate collaborative learning and give support to teachers, lecturers and business (TELISA, 1998). These centers were meant to involve partnerships with business, industries and government to promote distance education. Some such centers have become operational.

We support setting up of such ICT distance learning centers. We foresee the following benefits to be derived from such programmes. They can solve some of the foreseen and current technical and other technological problems associated with distance learning in Africa, shortage of Internet connections, and so forth. Using these centers as multimode distance learning centers can solve many of the other distance education problems, including the problem of the language barrier of English as second language. They can furthermore enable culturally suitable education by using facilitators who are aware of the needs of the particular population groups being served respectively. Electronic learning content can be updated more easily, while ensuring that all ICT learners receive culturally suitable educational material. Courses can more readily be adapted to local conditions. The latest technologies can become electronically available. Providing educational material electronically can lower the cost of distance learning programmes, thus reducing currency problems. The need for ICT technicians and educators in these centers can stimulate the numbers of ICT personnel educated and trained, which can also benefit business and industry in the long run.

Rapid technological changes occur in the ICT sector. Both ICT technicians and educators need to be up to date on developments. Education to these ends can only be successful in an environment where knowledge on fast changing technology is continually available. The multimode method proposed here will give ICT learners the opportunity to have access to knowledge available globally, and will thus ensure the sustainability of ICT training. An outcome of this multimode model of education will also be an increase in the awareness of ICT through education and training, thereby contributing to an environment conducive to further ICT education and training. General interest in ICT generated through education and training of learners using ICT as training medium, will also bootstrap further education and training in ICT.

The model, furthermore, has the potential of extending distance learning to other sectors of the African population, including people who need flexibility in learning times. People will have the opportunity to study at their own pace with the additional benefit of having face-to-face instruction. This will especially benefit women experiencing gender inequalities as well as certain other marginalized sections of the population, especially where their current circumstances or responsibilities prevent them from being part of continuous education programmes, since all of these will also be reachable for ICT training (Chale \& Michaud, 1997).

\section{Implementation of Multimode Learning in an ICT Programme}

During 2003 the multimode-training model was used for the implementation of the first and second year of an ICT degree at Technikon Pretoria in South Africa. Facilitators were appointed for all subjects and learning material was adapted for the Electronic Campus (EC), the e-learning environment used by the Faculty of ICT. This Electronic Campus is an educational environment similar to WebCT, developed internally by the staff of the Faculty. Two workshops per subject were scheduled and students were trained in the use of EC on the day of registration. Workshops included all practical demonstrations necessary.

Problems encountered during this first implementation were as follows:

- Technology : The Technikon's network infrastructure was not sufficiently reliable and quite often students could not access EC through the Internet. Internet connections by students attempting access from their homes were very slow and, in general, study material could not be downloaded. 
- Lecturers: Lecturers were not specifically trained in the multimode learning environment. This, in retrospect, was an essential condition for lecturers coming from a contact tuition environment being successful in this new environment. Further more, there was a lack of communication between lecturers and students due to failures in technology and the misconception by lecturers that students could cope on their own in the e-learning mode.

- Students: The expectations of some students were that participating in workshops will be enough for mastering the material. They did not follow the suggested study programme and did not prepare enough for the workshops. This might be attributed to the perception that, since the institution is a residential institution, contact time will be enough to master the learning material.

- Workshops: We found that for primarily theoretical subjects two (face-to-face) workshops per module were sufficient. In the case of subjects where more logical skills development is required and which are generally relatively more difficult for students, e.g. mathematics and programming, students became discouraged due to lack of support and slow progress. The pass rates for these subjects averaged approximately $30 \%$ as opposed to the other subjects for which the pass rates were all more than $60 \%$.

- Learning material: The learning material was not sufficiently interactive to stimulate the students and virtual classrooms were not used in all subjects. This contributed to lack of progress by students.

One conclusion after the first semester of implementation was that the mix or ratio of on-line to face-to-face contact opportunities per semester module must be customised according to subject content. For programming and mathematical subjects we experienced a need for workshops on a more regular basis: at least one workshop every two to three weeks. Students also need to receive study material on a $\mathrm{CD}$ at registration, to overcome the access problems. Evaluation of these interventions will take place by the end of this semester.

\section{Conclusion}

We have here argued for introduction of a certain multimode method of ICT learning and training. We perceive that the concept of distance learning by advanced educational technology is at present only emerging in Africa. This applies particularly to education and training in ICT.

Learners in Africa tend to have difficulties in understanding the technologies underpinning the ICT era. We suggest that a learner support system needs to be put in place to assist students in using relevant technologies. Research has shown that distance learning requires much selfdiscipline on the part of students. Compared to conventional learning, students tend to become more isolated in distance-learning programmes. We recommend a multimode strategy incorporating both extensive face-to-face learning and e-learning, into the traditional distance learning environments. This strategy, we believe, can reduce the negative factors in distance learning and can ensure successful completion of self-study programmes to increase the number of competent ICT specialists in Africa. This strategy can be implemented for studies in the information technology environment but needs to be customised according to subject content.

\section{References}

Centre for Lifelong Learning. (1998, July). TELISA concept document. Retrieved February 27, 2003, from http://pgw.org/telisa/Concept_Document/concept_document_9807.htm

Chale, M. \& Michaud, P. (1997). Distance learning for change in Africa. The Acacia initiative - Studies and Outputs, International Development Research Centre. Retrieved February 27, 2003, from http://www.idrc.ca/acacia/03230/04-dlear/dlear4.html 
Darkwa, O. \& Mazibuko, F. (2000). Creating virtual learning communities in Africa: challenges and pros pects. First Monday, 5 (5). Retrieved January 26, 2003, from http://firstmonday.org/issues/issue5_5/darkwa/index.html

Diallo, A. B. (n.d.). Technology, Africa and learning, Opinion Article 3, UNESCO - Division of Basic Education. Retrieved February 27, 2003, from http://www.unesco.org/education/educprog/lwf/doc/portfolio/opinion3.htm

Gilpin,V. (2000). Best practice in innovative learning: Information technology as a catalyst for change: A summary of recent Africa experience. Focus On Africa. Retrieved February 27, 2003 from http://www.crite.net/conferenes/2000/iscl/Focus on Africa.html

Information technology transfer to developing countries - Is it really taking place? (n.d.). Retrieved March 12, 2003, from UAICT - Africa subject Listing for Information technology, http://celi.lub.lu.se/htdocs/subject-listing/informationtechnology.html

Ivala, E. (1999). The Internet and distance education, $I^{\text {st }}$ NADEOSA Conference. Retrieved March 12, 2003 from http://www.saide.org.za/nadeosa/conference1999/ivala.htm

Lelliot, A. \& Enslin, P. (2000). Online education in Africa - Promises and pitfalls. Journal of Philosophy of Education Special Issue: Enquiries at the Interface: Philosophical Problems of online Education, 34. Retrieved February 27, 2003, from http://generalupdate.rau.ac.za/infosci/conf/Wednesday/Lelliot.htm

Murphy, P., Anzalone, S., Bosch, A. \& Moulton, J. (2002). Enhancing learning opportunities in Africa: Distance education and information and communication technologies for learning. African Region Human Development Working Paper Series (24051) Africa Region: The World Bank.

Mundy, P. \& Sultan, J. (2001). Information revolution: How information and communications management is changing the lives of rural people. Wageningen, The Netherlands: CTA.

Odedra-Straub, M. (1990). Information technology transfer to developing countries: Is it really taking place?" In J. Berleur and J. Drumm (Eds.), Information technology assessment. North-Holland. Retrieved March 7, 2003, from http://www.straub-odedra.de/Seiten/publications.htm

Odedra-Straub, M. (2002). The way forward, Report on the IFIP WG 9.4 Conference, The Electronic Journal on Information Systems in Developing Countries, 10(1). Retrieved February 27, 2003 from http://www.is.cityu.edu.hk/research/ejisdc/vol10/v1011.pdf

Southern Africa Global Distance Educationet. (1999). An overview of distance education initiatives and the use of technology in Malawi, Retrieved February 27, 2003, from the SAIDE Web Site:

http://www.saide.org.za/worldbank/countries/malawi/maloverview.htm

\section{Biographies}

Joey Jansen van Vuuren initially started her studies at Potchefstroom University obtaining a degree in Music and Mathematics as well as a Higher Diploma in Education. After one year of teaching she changed to Industrial Engineering. While starting her part time studies in IT she worked for several years in both Industrial Engineering and IT. After obtaining her BSc in Computer Science and Operational Research and her BSc Honours she started her Tertiary Education career at Technikon Witwatersrand, UNISA and Technikon Pretoria. After Completion of her MSc she moved into management and therefore changed her study focus to management and studies for an MBA. During this time her research focused on the trends in the IT industry as well as E-learning. She is currently busy with research for a doctoral degree with specialisation in datamining and security.

Dr. Petrie Coetzee is a principal lecturer at the Business Applications Department, Faculty ICT, Tswhane University of Technology, Pretoria RSA. He focuses on research and has several postgraduate students. His research focus is on Knowledge Management and IT Innovation. 